\title{
The Multiple Sclerosis Health Resource Utilization Survey (MS-HRS): Development and Validation Study
}

Nils-Henning Ness ${ }^{1}$, MSc; Rocco Haase ${ }^{1}$, Dipl-Psych; Raimar Kern ${ }^{2}$, BA; Dirk Schriefer ${ }^{1}$, MSc; Benjamin Ettle ${ }^{3}$, $\mathrm{PhD}$; Christian Cornelissen ${ }^{4}$, PhD; Katja Akguen ${ }^{1}, \mathrm{MD}$; Tjalf Ziemssen ${ }^{1}$, MD

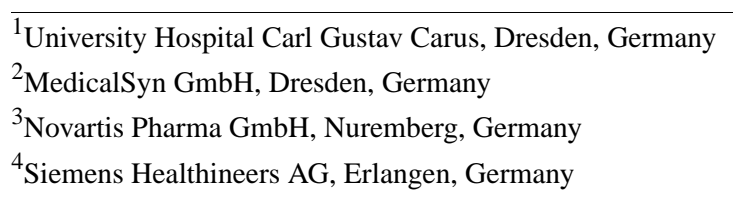

Corresponding Author:

Tjalf Ziemssen, MD

University Hospital Carl Gustav Carus

Fetscherstr. 74

Dresden, 01307

Germany

Phone: 493514584465

Email: tjalf.ziemssen@uniklinikum-dresden.de

\section{Abstract}

Background: Survey-based studies are frequently used to describe the economic impact of multiple sclerosis (MS). However, there is no validated health resource survey available, preventing comparison of study results and meaningful conclusions regarding the efficiency of long-term treatments.

Objective: The aim of this study was to develop and validate a tablet- and paper-based MS health resource utilization survey.

Methods: We developed and validated the Multiple Sclerosis Health Resource Utilization Survey (MS-HRS), consisting of 24 cost items for paper and tablet users. Data for validation came from two large German observational studies. Survey practicability was assessed according to the response rate. Reliability was described using test-retest reliability as well as Guttman lambda. Construct validity was assessed as convergent and discriminant validity via correlations with associated patient-reported outcomes and known-group analyses.

Results: In total, 2207 out of 2388 (response rate: 92.4\%) patients completed the survey and were included to determine psychometric properties. The test-retest reliability had an intraclass correlation coefficient of 0.828 over a course of 3 months. Convergent validity analyses showed that total costs correlated positively with increased disability $(r=0.411, P<.001)$. For discriminant validity, correlations of total costs with the Treatment Satisfaction Questionnaire for Medication ranged from -0.006 (convenience) to -0.216 (effectiveness). The mean annual cost was $€ 28,203$ (SD $€ 14,808$ ) (US $\$ 39,203$; SD US \$20,583) with disease-modifying therapies.

Conclusions: The MS-HRS is a multilingual, reliable, valid, electronically available, and easy-to-administer questionnaire providing a holistic cross-sectional and longitudinal assessment of resource utilization in patients with MS.

(J Med Internet Res 2020;22(3):e17921) doi: $10.2196 / 17921$

\section{KEYWORDS}

multiple sclerosis; patient-reported outcome measures; resource utilization; validation; questionnaire development

\section{Introduction}

Multiple sclerosis (MS) is a potentially severe cause of neurological disability throughout adult life, leading to many years with high economic burden of the disease [1]. Studies on resource utilization in patients with MS have analyzed secondary data, such as administrative data of health insurance or health care providers, which have several strong limitations [2]. First, data accuracy may not be sufficient as several health care services can, but should not, be combined under one capitation. Second, the societal perspective cannot be considered, as only a share of all costs is refunded. In complex diseases like MS, patients' needs exceed the scope of primary and secondary 
health care providers, making a societal perspective even more important [3]. Third, billing data do not include important clinical data, making it impossible to determine the reasons for cost increases in the investigated population.

As another approach, diaries are commonly used to prospectively gather information on patient-level data [3]. However, the challenges in using diaries are thoroughness in reporting and high drop-out rates in time periods longer than 1 year [4].

Questionnaire-based cross-sectional studies represent a third well-recognized way of cost assessment in MS research, and they are well suited to analyze the occurrences of certain utilization behaviors [4-11]. Such surveys have the potential to include all relevant cost dimensions and may be applied to several stakeholders of the health care process. For instance, disease-modifying therapies (DMTs) are the main cost drivers for patients in earlier disease stages, and indirect costs are mainly responsible for the economic burden in later disease stages. However, cross-sectional investigations cannot assess the temporal associations between an intervention and an outcome. Such objectives require longitudinal data, which are fundamental for health economic evaluations, such as cost-effectiveness studies. Despite the long tradition of health economic evaluations in MS, there is no validated questionnaire with sufficient psychometric properties available, preventing comparison of study results between populations and meaningful conclusions [12,13].

The aim of our work was to develop and validate an easy to administer questionnaire that provides a holistic longitudinal assessment of resource utilization for clinical practice and elaborate research approaches.

\section{Methods}

\section{Questionnaire Development}

A German expert group consisting of neurologists, health care administrators, psychologists, and MS nurses developed the first version of the Multiple Sclerosis Health Resource Utilization Survey (MS-HRS) at the University Hospital Dresden in 2009. Following intensive feedback from physicians, nurses, and patients, a second more time-efficient version was created in 2016. The requirements from clinical practice, such as time-saving use in everyday clinical practice, updatable pricing, and avoidance of double documentation, were decisive for the development of the digital version, which is browser-based and can be used across most devices (Figure 1). The time-saving use was realized through an adaptive questionnaire structure by presenting only the necessary items electronically. 
Figure 1. Image of the tablet app of the German version of the Multiple Sclerosis Health-Resource Utilization Survey.

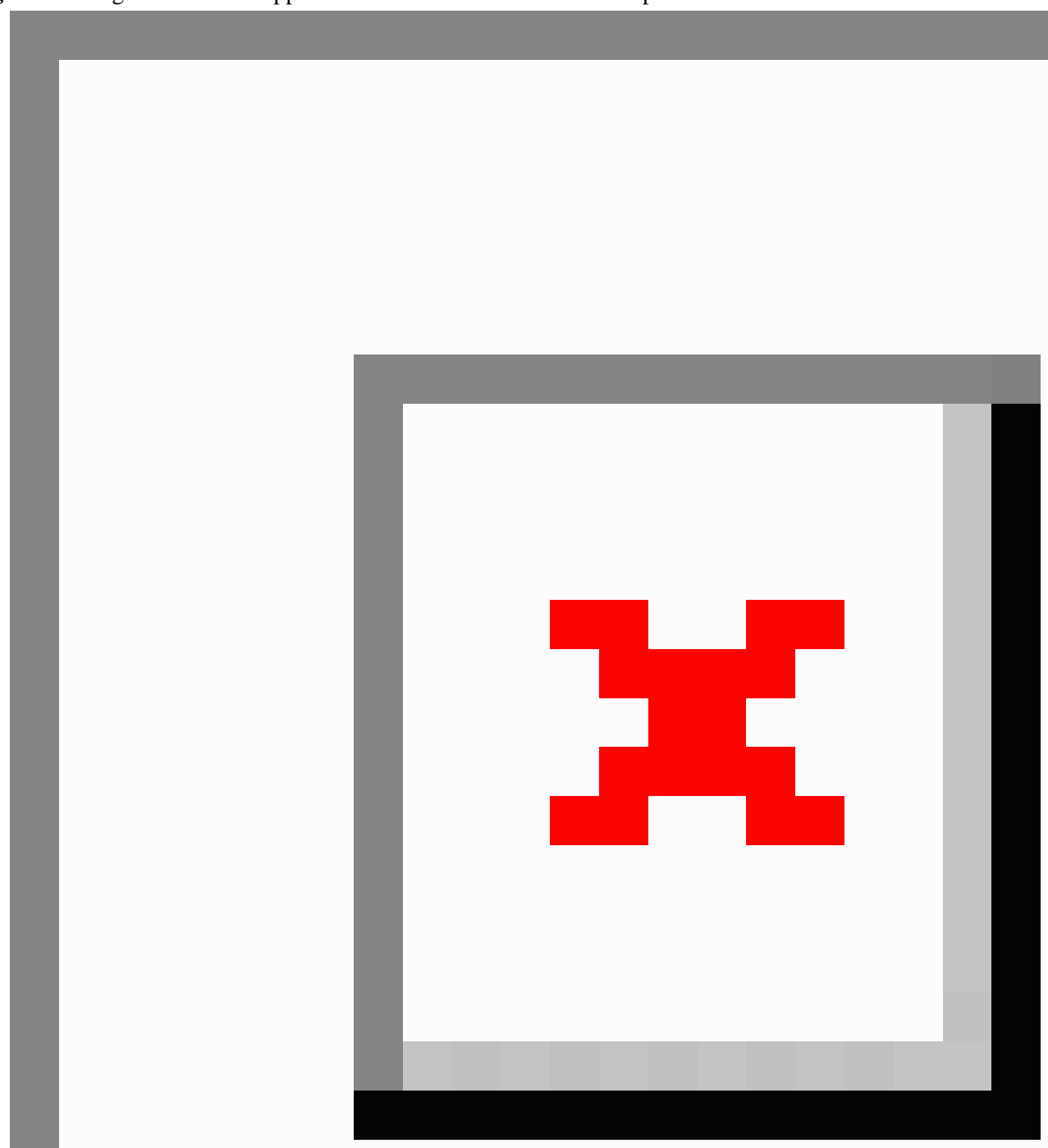

The current digital German and translated English versions of the MS-HRS are in line with the recommendations on the core elements of a standardized resource questionnaire and can be completed in 10 to 15 minutes [14].

Health economic analysis can be performed from different perspectives with the societal perspective being the broadest [15]. For the practical evaluation of costs, three steps are considered, namely identification of resource consumption, quantification of resource use, and valuation of resources [15].

\section{Identification of Resource Consumption}

Information on resource consumption was obtained from studies, guidelines, textbook knowledge, administrative and accounting data, and expert opinions $[4,8,16,17]$.

Costs were classified into direct medical, direct nonmedical, and indirect costs, according to German health technology assessment guidelines. Keeping multiple use cases in mind, we divided the tool into a core and an additional set of items (Table 1). The core elements are constitutive for the health resource utilization model and sufficient to capture the scope of resource utilization, whereas the additional questions foster the understanding of resource utilization. 
Table 1. Core items of the Multiple Sclerosis Health Resource Utilization Survey: content and response option.

\begin{tabular}{|c|c|c|}
\hline Domain (number of questions) and question label & Item & Response option \\
\hline \multicolumn{3}{|l|}{ Direct medical costs (5) } \\
\hline Inpatient stays & $\begin{array}{l}\text { Stays in a hospital, especially in a neurological ward, reha- } \\
\text { bilitation clinic, and nursing home }\end{array}$ & Number of stays \\
\hline Outpatient stays & $\begin{array}{l}\text { Stays in a hospital, especially in a neurological ward, reha- } \\
\text { bilitation clinic, and nursing home }\end{array}$ & Number of stays \\
\hline Professional consultations & $\begin{array}{l}\text { Contact with neurologists, other specialists, multiple sclerosis } \\
\text { nurses, physiotherapists, occupational therapists, counselling } \\
\text { centers, opticians, speech therapists, acupuncturists, other } \\
\text { alternative health care professionals, and others }\end{array}$ & Number of contacts \\
\hline Examinations & $\begin{array}{l}\text { Examinations undergone: magnetic resonance imaging, } \\
\text { computed tomography, lumbar puncture, and blood exami- } \\
\text { nations }\end{array}$ & Number of examinations \\
\hline Over-the-counter medication & & Expenditure in Euro \\
\hline Medical consumables & & Expenditure in Euro \\
\hline Professional care & Assistance from professional caregiver and home help & Number of hours per week \\
\hline \multicolumn{3}{|l|}{ Direct nonmedical costs (2) } \\
\hline Informal care & Assistance from friends and family members & Number of hours per week \\
\hline Investments and purchases & $\begin{array}{l}\text { Investments and purchases: housing, car modifications, } \\
\text { walking aids, manual wheelchair, automatic wheelchair, } \\
\text { scooter, bed, and others }\end{array}$ & Expenditure in Euro \\
\hline \multicolumn{3}{|l|}{ Indirect costs (3) } \\
\hline Employment & Total hours of working time per week & Number of hours \\
\hline Employment: Sick leave & Days of sick leave & Number of days \\
\hline Employment: Presenteeism & Extent of reduced productivity at work & Likert scale $(0-10)$ \\
\hline Employment: Disability pension & Extent of disability pension & Percentage \\
\hline
\end{tabular}

\section{Quantification of Resource Use}

We used the most accurate method of microcosting defined as "direct enumeration and costing out of every input consumed in the treatment of a particular patient" to quantify resources (Table 2) [18]. Recall periods of resource utilization have been determined to avoid over- and underreporting. Longer recall periods lead to telescoping effects, in which events occurring outside the time frame are mistakenly included in the intended period [19]. Furthermore, we took into account that more frequent events and those that are less salient are less likely to be recalled accurately over a long period. In conclusion, the recall period may differ with respect to the nature of cost items but should never exceed 12 months. We recommend intervals for the assessment between 3 and 6 months. It is noticeable that unified recall periods across all items of the survey made the questionnaire more intelligible for patients. In our results, we report all calculated costs as per quarter. 
Table 2. Health resources and quantification.

\begin{tabular}{|c|c|c|}
\hline Domain & Item & Valuation \\
\hline \multicolumn{3}{|l|}{ Direct medical costs } \\
\hline Inpatient care/day admission & Days in hospital, rehabilitation, and nursing wards & Standardized cost units \\
\hline Ambulant consultations & $\begin{array}{l}\text { Visits to general practitioners, neurologists, others specialists } \\
\text { (urologists, ophthalmologists, and psychiatrists), multiple sclerosis } \\
\text { nurses, physical therapists, psychologists, occupational therapists, } \\
\text { opticians, speech therapists, acupuncturists, and other alternative } \\
\text { healing professionals }\end{array}$ & Standardized cost units \\
\hline Investigations/diagnostics & $\begin{array}{l}\text { Magnetic resonance imaging, computed tomography, spinal tap, } \\
\text { blood tests, and others }\end{array}$ & Physicians' fee schedule \\
\hline Over-the-counter medication & Medication and recommending doctor & Patient reported \\
\hline Disease-modifying therapies & & $\begin{array}{l}\text { Annual therapy costs as calculated } \\
\text { from medication reports }\end{array}$ \\
\hline Home help and support of professionals & Professional help, household care, and personal assistance & Human capital approach \\
\hline Medical consumables & Medical consumables & Patient reported \\
\hline \multicolumn{3}{|l|}{ Direct nonmedical costs } \\
\hline Investments and equipment & $\begin{array}{l}\text { House and car modifications, walking aids, wheelchair (manual } \\
\text { and electric), scooter, sickbed, and others; payer and grants }\end{array}$ & Patient reported \\
\hline Informal care & $\begin{array}{l}\text { Time taken for preparation of meals, climbing stairs, personal care, } \\
\text { drug administration, transport, and others; reduction of working } \\
\text { hours of relatives }\end{array}$ & Opportunity costs method \\
\hline \multicolumn{3}{|l|}{ Indirect costs } \\
\hline Employment and labor productivity & $\begin{array}{l}\text { Full or part time work, sick leaves, reduced working time, change } \\
\text { of work, and loss of earning }\end{array}$ & Human capital approach \\
\hline Employment and labor productivity & $\begin{array}{l}\text { Absence hours (multiple sclerosis and others), total working hours, } \\
\text { and productivity scale }\end{array}$ & Human capital approach \\
\hline
\end{tabular}

\section{Valuation of Resources}

Evaluations conducted from societal perspectives are intended to reflect societal opportunity costs, which are equal to market prices in perfectly competitive markets. Nevertheless, markets in the health care sector are imperfect owing to statutory regulations. Hence, societal opportunity costs have to be approximated in most cases. Therefore, data from Bock et al were used wherever available (Table 3) [20].

Owing to a lack of data, few valuations were calculated from existing values. Visiting a nurse was rated with the lowest monetary value of $€ 16.42$. Furthermore, psychologist contact was monetarily valued as visiting a psychotherapist. The valuation for other specialists (eg, psychiatrist, urologist, and optician) was calculated as the mean of the given examples. Societal opportunity costs for investigations were approximated from the physicians' fee [21].

To calculate annual costs for DMTs, we used defined daily dose net costs multiplied by 365 days [22]. Net costs account for statutory manufacturer discounts as well as pharmacy discounts (Table 4). The work productivity loss (absenteeism, early retirement, and presenteeism) was calculated using the human capital approach [23]. Absenteeism was defined as not showing up for work, whereas presenteeism was defined as reduced work productivity due to health problems. The loss resulted from the total number of lost hours multiplied by the average salary per hour. Any hour not worked was considered as lost. Data for this calculation were obtained from official statistics [24].

In 2011, 233 working days were used for the calculation, and the average number of working hours was 1406.2 hours [25]. Additionally, the average hourly labor cost was $€ 29.90$ [20]. The monetary work productivity loss due to sick leave was calculated as follows:

Productivity loss $=(1406.2$ working hours $/ 233$ working days) $\times € 29.90$ hourly salary

Occupational disability was calculated as the product of daily wage, average number of working days, and percentage of disability, with a maximum of $€ 42,045.38$ per year. The maximum hours dedicated to informal care was set to 60 hours per week according to German policies.

To ensure comparability of cash flows, prices from different periods were adjusted to the 2011 price level using the general price index for the national economy. This applies to patients' self-reported medications, investments, medical consumables, and DMTs. Consumption of the remaining resources was valued with prices from the year 2011 to generate comparable costs within our validation population. For other purposes, more recent values may be derived by applying a conventional cost inflation of $2 \%$.

All costs are reported in Euro. In 2011, the Euro to US dollar annual average exchange rate was equal to 1.392 . 
Table 3. Resource valuation per unit.

\begin{tabular}{|c|c|}
\hline Cost category & Monetary valuation \\
\hline \multicolumn{2}{|l|}{ Direct medical costs (inpatient) } \\
\hline Hospital & $€ 593.04$ \\
\hline Rehabilitation & $€ 121.85$ \\
\hline Nursing & $€ 69.80$ \\
\hline \multicolumn{2}{|l|}{ Direct medical costs (outpatient) } \\
\hline Hospital & $€ 385.48$ \\
\hline Rehabilitation & $€ 46.68$ \\
\hline Nursing & $€ 46.15$ \\
\hline \multicolumn{2}{|l|}{ Direct medical costs (ambulant consultations) } \\
\hline General practitioner & $€ 20.06$ \\
\hline Neurologist & $€ 44.72$ \\
\hline Other specialists & $€ 34.73$ \\
\hline Nurse & $€ 16.42$ \\
\hline Physiotherapist & $€ 16.42$ \\
\hline Psychologist & $€ 78.08$ \\
\hline Occupational therapist & $€ 37.51$ \\
\hline Optician & $€ 34.78$ \\
\hline Speech therapist & $€ 38.59$ \\
\hline Acupuncturist & $€ 18.24$ \\
\hline Other alternative healing professionals & $€ 27.40$ \\
\hline \multicolumn{2}{|l|}{ Direct medical costs (investigations/diagnostics) } \\
\hline Magnetic resonance imaging & $€ 120.21$ \\
\hline Computed tomography & $€ 73.78$ \\
\hline Lumbar puncture & $€ 38.90$ \\
\hline Blood tests & $€ 1.10$ \\
\hline Others & $€ 60.66$ \\
\hline Direct medical costs (over-the-counter medication) & Patient reported \\
\hline Direct medical costs (disease-modifying therapy) & See Table 4 \\
\hline Direct medical costs (medical consumables) & Patient reported \\
\hline Direct medical costs (home help/professional care) & $€ 27.57$ \\
\hline \multicolumn{2}{|l|}{ Direct nonmedical costs } \\
\hline Equipment, aids, and modifications & Patient reported \\
\hline Informal care & $€ 21.09$ \\
\hline \multicolumn{2}{|l|}{ Indirect costs } \\
\hline Sick leave & $€ 180.45$ \\
\hline Disability pension (full year) & $€ 42,045.38$ \\
\hline
\end{tabular}


Table 4. Costs of disease-modifying therapies per year (in €).

\begin{tabular}{llllllll}
\hline Year & AVO $^{\mathrm{a}}$ & REB & BET & EXT & COP & GIL $^{\mathrm{f}}$ & TYS $^{\mathrm{d}}$ \\
\hline 2010 & 18069.27 & 22626.46 & 17977.14 & 15528.45 & 16623.45 & N/A & 24625.10 \\
2011 & 18611.35 & 23305.25 & 18516.45 & 15994.30 & 17122.15 & $26698.58^{\mathrm{i}}$ & 25363.85 \\
2012 & 18182.19 & 22900.46 & 18132.07 & 15604.68 & 16377.93 & 25907.56 & 24586.58 \\
2013 & 17981.00 & 22765.35 & 17815.29 & 15431.93 & 16197.00 & 22571.44 & 24214.41 \\
2014 & 19437.31 & 24432.98 & 17601.95 & 15441.48 & 17035.61 & 18965.36 & 26194.92 \\
2015 & 19333.96 & 24155.25 & 17517.70 & 15370.25 & 16733.32 & 20393.73 & 24280.75 \\
2016 & 19247.42 & 23987.27 & 17384.09 & 14680.25 & 16648.48 & 21516.72 & 23321.06 \\
2017 & 18865.10 & 23529.38 & 17047.81 & 15715.49 & 16352.26 & 20784.68 & 22902.02 \\
\hline
\end{tabular}

aVO: Avonex.

${ }^{b}$ REB: Rebif.

${ }^{\mathrm{c}}$ BET: Betaferon.

${ }^{\mathrm{d}}$ EXT: Extavia.

${ }^{\mathrm{e}}$ COP: Copaxone.

${ }^{\mathrm{f}}$ GIL: Gilenya.

$\mathrm{g}_{\text {TYS: Tysabri. }}$

${ }^{\mathrm{h}} \mathrm{N} / \mathrm{A}$ : not applicable.

${ }^{\mathrm{i}}$ As listed in the technology assessment report.

\section{Study Population}

Patients with relapsing-remitting MS (RRMS) were recruited in two prospective noninterventional multicenter studies conducted in Germany [26,27]. In that context, assessments of medical history and other general data, such as the Expanded Disability Status Score (EDSS), were performed by the treating neurologist. The current analyses are limited to patients with an EDSS of 0-6.0 to ensure sufficiently large subpopulations. Approval for both studies was obtained from independent local ethics committees, and all patients provided written informed consent for the collection of data [26,27].

\section{Practicability and Reliability}

Practicability was determined by the response rate of patients completing the MS-HRS. In addition, we compared the characteristics of completers and noncompleters to avoid selection bias. For reliability and validity analyses, we focused on the core elements of the survey. As we did not intend to evaluate DMTs at this step, costs for DMTs were not part of our methodological evaluation, which focused on psychometric properties.

For reliability analysis, test-retest reliability of the total costs in a group of stable patients over 3 months was estimated. Stable patients were defined as those not having relapse or increase in the EDSS during the 3 months of the retest period and another 3 months prior to the assessment. Thresholds for intraclass correlation coefficient (ICC) were applied as recommended (ICC <0.5: poor reliability; $0.5 \leq \mathrm{ICC}<0.75$ : moderate reliability; $0.75 \leq \mathrm{ICC}<0.9$ : good reliability; and ICC $>0.90$ : excellent reliability) [28]. Guttman lambda 2 and lambda 6 are reported for the monetarized standardized items of the health resource utilization model with respect to the heterogeneous structure, providing a lower bound estimate of the consistency of the

pricing approach. In an ordinary setting for test construction, desired levels would lay above 0.7 . As our survey is not based on latent constructs but instead on real costs, consistency analysis is not part of the primary evaluation of reliability, but it provides additional insights for the model and the cost components.

\section{Validity}

Repeated expert consensus meetings of health economists, psychologists, and neurologists were conducted to secure face validity in terms of consistency and completeness.

Construct validity was assessed as convergent and discriminant validity via correlations with associated patient-reported outcomes (PROs) and known-group analyses by the EDSS (ranges: 0-1.0, 1.5-2.5, 3.0-4.0, and 4.5-5.5). The selected PRO measures were the EuroQol-5 Dimensions (EQ-5D), UK Neurological Disability Scale (UKNDS), and Patient Reported Outcome Indices for MS (PRIMUS) [29-32]. We expected to find significantly higher costs in groups with higher EDSS scores and correlations above 0.40 for convergent validity. As we did not intend to evaluate DMTs, the Treatment Satisfaction Questionnaire for Medication (TSQM) should present correlations clearly below 0.3 for discriminant validity [33].

\section{Statistical Analysis}

Continuous values are reported as arithmetic mean and SD. Ordinal values are reported as median and IQR. One-way random ICCs were used to calculate estimates for the test-retest reliability. All other correlations were calculated with Spearman rank correlation coefficients. Kruskal-Wallis $\mathrm{H}$ tests were conducted for known group analyses. Mann-Whitney U tests with adjustments by Bonferroni correction for multiple tests were applied for pairwise comparisons. All reported $P$ values 
were compared to an alpha error level of $5 \%$. No imputations were made for missing values.

\section{Results}

\section{Patient Characteristics}

In total, 2207 of 2388 patients completed the questionnaire at baseline and were therefore included in the validation process. The study population had a mean age of 41.73 (SD 10.19) years and was mostly female $(1609 / 2207,72.90 \%)$ (Table 5). Employed patients $(1347 / 2207,61.03 \%)$ were working predominantly full time $(794 / 1347,58.95 \%)$.

In terms of relapses within the previous year, active (1015/2207, $45.99 \%)$ and nonactive $(1192 / 2207,54.01 \%)$ patients were balanced in the population. Participants reported a mean disease duration since diagnosis of 7.54 (SD 6.11) years and a mean EDSS of 2.43 (SD 1.57).

Table 5. Characteristics of the study population $(\mathrm{N}=2207)$.

\begin{tabular}{|c|c|}
\hline Parameter & Value \\
\hline \multicolumn{2}{|l|}{ Age, years } \\
\hline Mean (SD) & $41.73(10.19)$ \\
\hline Median (IQR) & $42.00(34.00-49.00)$ \\
\hline \multicolumn{2}{|l|}{ Gender } \\
\hline Female, n (\%) & $1609(72.90 \%)$ \\
\hline \multicolumn{2}{|l|}{ Employment } \\
\hline Employed, n (\%) & $1347(61.03 \%)$ \\
\hline Full-time employed, n (\%) & $794(58.95 \%)$ \\
\hline \multicolumn{2}{|c|}{ Number of relapses in the previous year, $n(\%)$} \\
\hline 0 & $1192(54.01 \%)$ \\
\hline 1 & $612(27.73 \%)$ \\
\hline 2 & $267(12.10 \%)$ \\
\hline$\geq 3$ & $98(4.44 \%)$ \\
\hline Unknown & $38(1.72 \%)$ \\
\hline \multicolumn{2}{|c|}{ Duration of disease since diagnosis, years } \\
\hline Mean (SD) & $7.54(6.11)$ \\
\hline Median (IQR) & $6.00(3.00-11.00)$ \\
\hline \multicolumn{2}{|l|}{$\mathbf{E D S S}^{\mathbf{a}}$} \\
\hline Mean (SD) & $2.43(1.57)$ \\
\hline Median (IQR) & $2.00(1.00-3.50)$ \\
\hline
\end{tabular}

${ }^{a}$ EDSS: Expanded Disability Status Score.

\section{Validation of the Questionnaire}

\section{Practicability}

Looking at the number of patients completing the questionnaire, a good response rate of $92.4 \%$ (2207/2388) was achieved. Therefore, the responses of 2207 patients could be used to calculate total costs and all other parts of the health resource model. Noncompleting patients $(n=181)$ did not differ in their gender distribution, age, or EDSS, but presented a slightly longer disease duration (mean 9.67 [SD 7.21] years, $P<.001$ ).

\section{Reliability}

Reliability was mainly assessed as test-retest reliability in a stable subgroup of patients. Overall, 1192 of 2207 (54.01\%) patients fulfilled the criterion of presenting stable MS within that period. The ICC for this group over a course of 3 months was 0.828. In addition, Guttman lambda $2(\lambda 2=0.679)$ and lambda $6(\lambda 6=0.694)$ indicated an acceptable consistency between the standardized monetarized items of the health resource model (excluding DMT costs).

\section{Validity}

We analyzed the construct validity for total costs of the MS-HRS via known groups (excluding DMT costs). In all four EDSS groups, we found significantly different MS-related total costs and subcosts (all $P<.001$; Table 6). Further, all pairwise comparisons indicated significant differences in the direction as expected before (all $P<.001$ for total costs, all $P<.05$ for subcosts; Table 6). 
Table 6. Known-group analysis: health resource utilization costs of patients with multiple sclerosis per quarter by disability (N=2059).

\begin{tabular}{lllllllllllll}
\hline \multirow{2}{*}{ Parameter } & \multicolumn{2}{c}{ EDSS $^{\mathrm{a}} 0-1.0(\mathrm{n}=562)$} & \multicolumn{2}{c}{ EDSS $1.5-2.5(\mathrm{n}=756)$} & \multicolumn{2}{c}{ EDSS 3.0-4.0 (n=589) } & \multicolumn{2}{c}{ EDSS 4.5-5.5 (n=152) } \\
& Mean & SD & Median & Mean & SD & Median & Mean & SD & Median & Mean & SD & Median \\
\hline Total cost $(€)$ & 1099 & 2211 & 150 & 2295 & 3647 & 585 & 3112 & 3979 & 1334 & 4733 & 4639 & 4158 \\
Direct medical cost $(€)$ & 309 & 910 & 99 & 541 & 1724 & 165 & 789 & 1998 & 249 & 1003 & 2295 & 411 \\
Direct nonmedical cost $(€)$ & 12 & 108 & 0 & 20 & 154 & 0 & 45 & 152 & 0 & 158 & 428 & 0 \\
Indirect cost $(€)$ & 777 & 1822 & 0 & 1734 & 2820 & 0 & 2280 & 3178 & 127 & 3572 & 3572 & 3637 \\
\hline
\end{tabular}

${ }^{\mathrm{a}}$ EDSS: Expanded Disability Status Score.

${ }^{\mathrm{b}}$ Disease-modifying therapies are not included in direct medical cost.

Convergent validity analyses showed that total costs correlated positively with increased (patient-reported) disability (UKNDS sum score: $r=0.411$ ) and lost ability to participate in daily routines and activities (PRIMUS Activities: $r=0.423$ ) and negatively with health-related quality of life (PRIMUS QoL: $r=0.350$; EQ-5D: $r=-0.342)($ all $P<.001)$.

For discriminant validity, correlations of total cost with TSQM scores ranged from -0.006 (convenience) to -0.216 (effectiveness). As expected, the inclusion of DMT costs lowered the correlations with all PROs (by 0.07 on average), but the relations between correlations were maintained.

\section{Resource Utilization}

Majority of patients stated that they used direct medical services in the past 3 months (Table 7). In contrast, less than every

second patient $(44 \%)$ had indirect medical costs and $16 \%$ had direct nonmedical costs. Besides DMTs, indirect costs were the main cost drivers ahead of direct medical and direct nonmedical costs.

Patients were mainly treated in private practices $(2068 / 2207$, $85 \%)$ and less often during inpatient hospital stays (138/2207, $6 \%$ ) and day care admissions $(65 / 2207,3 \%)$. However, the highest cost was for inpatient treatments (€315.06 [SD $€ 1587.09]$ ), followed by consultations in the primary sector ( $€ 209.87$ [SD $€ 292.73])$ and day admissions in hospitals ( $€ 32.22$ [SD €311.68]). Total costs per quarter averaged $€ 2462$ (SD $€ 3650$; median: €631) without DMTs and $€ 7126$ (SD $€ 3697$; median: €5871) with DMTs. Therefore, annual costs for mild-to-moderate RRMS ranged between €9528 (SD €14,603) without DMTs and $€ 28,203$ (SD $€ 14,808$ ) with DMTs. 
Table 7. Health resource utilization costs in patients with multiple sclerosis per quarter ( $\mathrm{N}=2207)$.

\begin{tabular}{ll}
\hline Variable & Value $^{\mathrm{a}}$ \\
\hline
\end{tabular}

Direct medical costs (without disease-modifying therapies)

$\begin{array}{ll}\text { Users, } \mathrm{n}(\%) & 2068(93.70) \\ \text { Mean (SD) } & 601.30(1708.55) \\ \text { Median (IQR) } & 174.00(75.00-417.50)\end{array}$

Inpatient care

$\begin{array}{ll}\text { Users, } \mathrm{n}(\%) & 138(6.25) \\ \text { Mean (SD) } & 315.06(1587.09) \\ \text { Median (IQR) } & 0.00(0.00-0.00)\end{array}$

Day admission

Users, $\mathrm{n}(\%)$

65 (2.95)

Mean (SD)

$32.22(311.68)$

Median (IQR)

$0.00(0.00-0.00)$

\section{Consultations}

Users, $\mathrm{n}(\%)$

1817 (82.33)

Mean (SD)

209.87 (292.73)

Median (IQR)

$109.50(44.72-268.32)$

\section{Examinations}

Users, n (\%)

$1429(64.75)$

Mean (SD)

$32.34(35.63)$

Median (IQR)

$30.05(0.28-45.77)$

Over-the-counter medication

Users, n (\%)

$693(31.40)$

Mean (SD)

$15.02(46.43)$

Median (IQR)

$0.00(0.00-10.00)$

Professional care

Users, n (\%)

$115(5.21)$

Mean (SD)

$7.02(44.79)$

Median (IQR)

(0.00-0.00)

Disease-modifying therapies

Users, n (\%)

$2185(99.00)$

Mean (SD)

4733.24 (820.30)

Median (IQR)

$4629.11(4280.54-5656.61)$

\section{Direct nonmedical costs}

Users, n (\%)

$352(15.95)$

Mean (SD)

44.65 (229.51)

Median (IQR)

$0.00(0.00-0.00)$

\section{Investments}

Users, n (\%)

$38(1.72)$

Mean (SD)

$9.14(165.80)$

Median (IQR)

$0.00(0.00-0.00)$

Informal care and community service

Users, n (\%) 


\begin{tabular}{|c|c|}
\hline Variable & Value $^{\mathrm{a}}$ \\
\hline Mean (SD) & $37.25(158.57)$ \\
\hline Median (IQR) & $0.00(0.00-0.00)$ \\
\hline \multicolumn{2}{|l|}{ Indirect costs } \\
\hline Users, n (\%) & $977(44.27)$ \\
\hline Mean (SD) & $1816.50(2880.74)$ \\
\hline Median (IQR) & $0.00(0.00-3037.00)$ \\
\hline \multicolumn{2}{|l|}{ Short-term absence } \\
\hline Users, n (\%) & $320(14.50)$ \\
\hline Mean (SD) & $441.53(1782.18)$ \\
\hline Median (IQR) & $0.00(0.00-0.00)$ \\
\hline \multicolumn{2}{|l|}{ Disability pension } \\
\hline Users, n (\%) & $352(15.95)$ \\
\hline Mean (SD) & $852.98(2062.98)$ \\
\hline Median (IQR) & $0.00(0.00-0.00)$ \\
\hline \multicolumn{2}{|l|}{ Presenteeism } \\
\hline Users, n (\%) & $475(21.52)$ \\
\hline Mean (SD) & $522.00(1333.18)$ \\
\hline Median (IQR) & $0.00(0.00-0.00)$ \\
\hline
\end{tabular}

${ }^{\mathrm{a}}$ All costs are in Euro.

\section{Discussion}

\section{Principal Findings}

The MS-HRS represents a reliable, valid, and easy-to-administer questionnaire providing a holistic assessment of resource utilization for patients with MS. Health resources were derived from all pathways of patients with MS in an adapted health resource model for MS.

Some very respectable efforts have already been taken to research the health economic footprint of MS [2,5-7]. In Europe, Kobelt et al repeatedly assessed the costs and burden of MS in a cross-sectional survey approach, including direct, indirect, and intangible costs [6,7]. Concepts and definitions of subcosts may differ over time with respect to scope and style of reporting (eg, intangible costs where a clear line is recommended) [34]. For our model approach, we gave strong emphasis to direct and indirect costs, as done by Karampampa et al and Reese et al in their models $[5,11]$. We increased the depth of the assessment of indirect costs by adding a quantification of costs for presenteeism in addition to costs for absenteeism (sick leave and disability pension).

Part of our questionnaire development was a validation process that confirmed reliability and validity in a way that no previous approach did within the MS domain (Figure 2). Kobelt et al also recognized the need for validation, but a systematic approach beyond the aspects of practicability and face validity remained a task to fulfil [35]. Even though we did not develop a one-dimensional questionnaire for a latent construct, we were able to demonstrate essential psychometric qualities in the health economic assessment of MS. As of today, a multidomain open-access database of resource-use questionnaires does not contain a published instrument for MS [12]. Most of the cost assessments for MS were not developed to be published for general use but developed for application in certain cross-sectional frameworks. A very recent analysis of real-life cost outcomes underlined the rising interest in longitudinal assessment of health resource utilization [10].

The proportion of patients claiming certain health services was slightly lower in the study by Kobelt et al than in this study [6]. The lower proportion of patients taking over-the-counter medications and investments was particularly noticeable. This may be explained by the less severe disease progression beyond a RRMS profile. Taking this into account, the average annualized disease burden was within the range expected from previous publications $[5,7,11,36]$.

Kobelt et al have recently reported precise price tags for most unit costs, and other authors have at least provided an indirect description of the valuation process and its exact results [5,9]. Differences were found for the valuation of subcosts, such as inpatient hospitalization, owing to different sources of valuation or different definitions for health resource units. In any case, precise and fully transparent reporting of per unit costs is highly recommended, especially for main cost drivers. 
Figure 2. Development and modification process of the Multiple Sclerosis Health-Resource Utilization Survey. ICC: intraclass correlation coefficient; $\lambda 2$ : Guttman lambda 2; $\lambda 6$ : Guttman lambda 6.

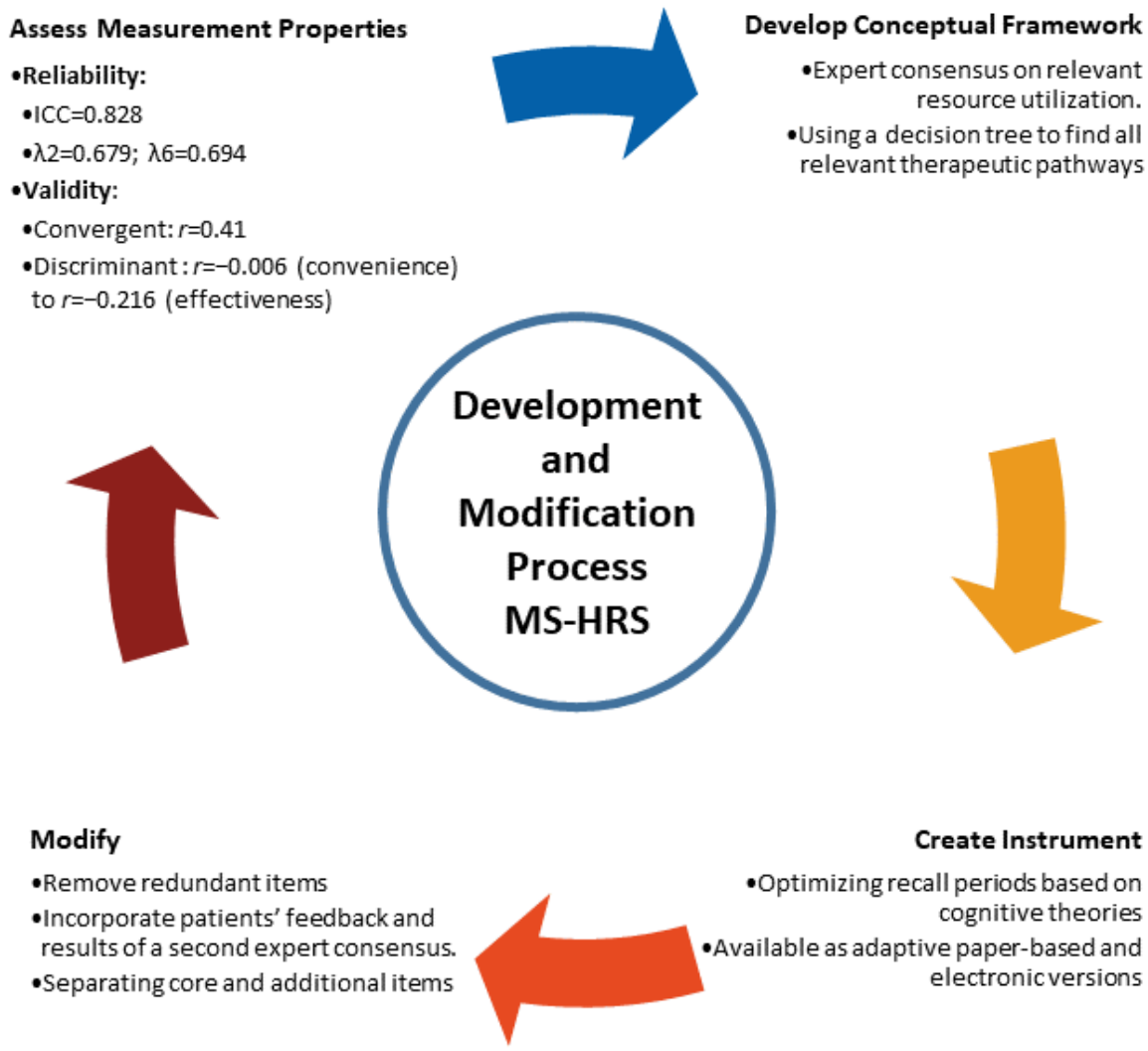

Event-related costing can also be considered to be of interest, but a clear separation from costs being assessed via routine data collection is necessary [5]. Otherwise, costs may double due to double assessment. We discussed whether to collect data for both sick days and missed working hours, as described by Reilly et al [16]. Furthermore, asking about sick hours would have meant switching to a recall period of 7 days, whereas the remaining questionnaire covers the last 6 months. Owing to higher usability, we decided to assess sick days only.

Claims data were considered for the assessment of criterion validity. However, there is a disadvantage that only billing-relevant data are available, preventing consideration of a societal perspective. Information on informal care, over-the-counter medication, and presenteeism and partial information on investments and medical consumables is not recorded. In addition, claims data do not provide the number of physician visits by a patient in Germany. In consequence, claims data were not suitable for the validation process.

Health economic studies often require both clinical and economic data. The MS-HRS can easily be used as part of clinical interventional and noninterventional studies to collect economic data. In a large population, we demonstrated that the questionnaire is easy to administer and has good psychometric properties. These characteristics provide the necessary prerequisites for high-quality health economic studies (eg, cost-effectiveness analyses).

\section{Limitations}

A patient-centered questionnaire is subject to notable limitations. Reliable recall periods of health resource use are time-limited, especially in patients who are cognitively more affected by the disease. Furthermore, patients may not want to disclose socioeconomic and health economic information because it is considered too confidential. We did not include information about more recent therapies as we did not gather related data for validation, which will be done in follow-up studies. Beyond this, further costs may be thinkable but less likely to have an impact on a societal level (eg, crowd-funded therapies at the current level and cost-related voluntary work loss). In addition, price tags for cost components have to be updated and adapted to local levels. For patients with progressive MS and patients with severe disability, further studies have to confirm the given psychometric properties.

\section{Conclusions}

The MS-HRS is a promising option to measure costs precisely in cross-sectional and longitudinal settings instead of estimating them or using surrogates. Further country-wise cost weights will facilitate the transparent estimation of MS-related costs across multiple regions. The MS-HRS is available online [37].

\section{Acknowledgments}

This study was funded by Novartis. 


\section{Authors' Contributions}

NHN and RH conceived the study; NHN and RH were responsible for methodology; NHN, RH, DS, and RK managed the software; RH, NHN, and DS were responsible for validation; NHN and RH performed formal analysis; NHN and RH performed investigations; TZ, CC, and BE were responsible for resources; NHN, RH, and DS were responsible for data curation; NHN wrote the original draft; RH, TZ, DS, CC, BE, RK, and KA reviewed and edited the manuscript; NHN was responsible for visualization; $\mathrm{TZ}$ was responsible for supervision; $\mathrm{TZ}$ was responsible for project administration; TZ, CC, and BE were responsible for funding acquisition. All authors have read and agree to the published version of the manuscript.

\section{Conflicts of Interest}

None declared.

\section{References}

1. Trisolini M, Honeycutt A, Wiener J, Lesesne S. Multiple Sclerosis International Federation.: RTI International; 2010. Global economic impact of multiple sclerosis URL: https://www.msif.org/wp-content/uploads/2014/09/

Global economic impact of MS.pdf [accessed 2020-02-28]

2. Ernstsson O, Gyllensten H, Alexanderson K, Tinghög P, Friberg E, Norlund A. Cost of Illness of Multiple Sclerosis - A Systematic Review. PLoS One 2016;11(7):e0159129 [FREE Full text] [doi: 10.1371/journal.pone.0159129] [Medline: 27411042]

3. Ridyard $\mathrm{CH}$, Hughes DA. Methods for the collection of resource use data within clinical trials: a systematic review of studies funded by the UK Health Technology Assessment program. Value Health 2010 Dec;13(8):867-872 [FREE Full text] [doi: 10.1111/j.1524-4733.2010.00788.x] [Medline: 20946187]

4. Fowler JFJ. Survey Research Methods (Applied Social Research Methods Series I). Thousand Oaks, CA: Sage Publications, Inc; 1993.

5. Karampampa K, Gustavsson A, Miltenburger C, Eckert B. Treatment experience, burden and unmet needs (TRIBUNE) in MS study: results from five European countries. Mult Scler 2012 Jun;18(2 Suppl):7-15. [doi: 10.1177/1352458512441566] [Medline: 22623122]

6. Kobelt G, Thompson A, Berg J, Gannedahl M, Eriksson J, MSCOI Study Group, European Multiple Sclerosis Platform. New insights into the burden and costs of multiple sclerosis in Europe. Mult Scler 2017 Jul;23(8):1123-1136 [FREE Full text] [doi: 10.1177/1352458517694432] [Medline: 28273775]

7. Kobelt G, Berg J, Lindgren P, Fredrikson S, Jönsson B. Costs and quality of life of patients with multiple sclerosis in Europe. J Neurol Neurosurg Psychiatry 2006 Aug;77(8):918-926 [FREE Full text] [doi: 10.1136/jnnp.2006.090365] [Medline: 16690691]

8. Kobelt G, Berg J, Lindgren P, Jönsson B. Costs and quality of life in multiple sclerosis in Europe: method of assessment and analysis. Eur J Health Econ 2006 Sep;7 Suppl 2:S5-13. [doi: 10.1007/s10198-006-0365-y] [Medline: 17310344]

9. Kobelt G, Eriksson J, Phillips G, Berg J. The burden of multiple sclerosis 2015: Methods of data collection, assessment and analysis of costs, quality of life and symptoms. Mult Scler 2017 Aug;23(2_suppl):4-16. [doi: 10.1177/1352458517708097] [Medline: 28643592]

10. Kobelt G, Jönsson L, Pavelcova M, Havrdová EK. Real-Life Outcome in Multiple Sclerosis in the Czech Republic. Mult Scler Int 2019;2019:7290285 [FREE Full text] [doi: 10.1155/2019/7290285] [Medline: $\underline{\text { 30911417] }}$

11. Reese JP, John A, Wienemann G, Wellek A, Sommer N, Tackenberg B, et al. Economic burden in a German cohort of patients with multiple sclerosis. Eur Neurol 2011;66(6):311-321. [doi: 10.1159/000331043] [Medline: 22086151]

12. DIRUM. 2020. Database of instruments for resource use measurement URL: http://www.dirum.org/instruments/all [accessed 2020-02-28]

13. Ridyard CH, Hughes DA, DIRUM Team. Taxonomy for methods of resource use measurement. Health Econ 2015 Mar;24(3):372-378. [doi: 10.1002/hec.3029] [Medline: 24442966]

14. Thorn JC, Brookes ST, Ridyard C, Riley R, Hughes DA, Wordsworth S, et al. Core Items for a Standardized Resource Use Measure: Expert Delphi Consensus Survey. Value Health 2018 Jun;21(6):640-649 [FREE Full text] [doi: 10.1016/j.jval.2017.06.011] [Medline: 29909868]

15. Drummond MF, Sculpher MJ, Claxton K, Stoddart GL, Torrance GW. Methods For The Economic Evaluation Of Health Care Programmes. Oxford, UK: Oxford University Press; 2015.

16. Reilly MC, Zbrozek AS, Dukes EM. The validity and reproducibility of a work productivity and activity impairment instrument. Pharmacoeconomics 1993 Nov;4(5):353-365. [doi: 10.2165/00019053-199304050-00006] [Medline: 10146874]

17. Fowler FJ. Improving Survey Questions: Design And Evaluation (Applied Social Research Methods). Thousand Oaks, CA: Sage Publications, Inc; 1995.

18. Raftery J. Costing in economic evaluation. BMJ 2000 Jun 10;320(7249):1597 [FREE Full text] [doi: $\underline{10.1136 / \mathrm{bmj} .320 .7249 .1597]}$ [Medline: 10845978]

19. Stull DE, Leidy NK, Parasuraman B, Chassany O. Optimal recall periods for patient-reported outcomes: challenges and potential solutions. Curr Med Res Opin 2009 Apr;25(4):929-942. [doi: 10.1185/03007990902774765] [Medline: 19257798] 
20. Bock J, Brettschneider C, Seidl H, Bowles D, Holle R, Greiner W, et al. [Calculation of standardised unit costs from a societal perspective for health economic evaluation]. Gesundheitswesen 2015 Jan;77(1):53-61. [doi: 10.1055/s-0034-1374621] [Medline: 25025287]

21. Kassenärztliche Bundesvereinigung. 2011. Einheitlicher Bewertungsmaßstab URL: https://www.kvsa.de/fileadmin/ user upload/PDF/Praxis/Honorarverteilung/EBM2011.pdf [accessed 2020-02-28]

22. Zeller W. Immuntherapeutika und zytostatika. In: Schwabe U, Paffrath D, editors. Arzneiverordnungs-Report 2012. Berlin, Heidelberg, GER: Springer; 2012:679-696.

23. van den Hout WB. The value of productivity: human-capital versus friction-cost method. Ann Rheum Dis 2010 Jan;69 Suppl 1:i89-i91. [doi: 10.1136/ard.2009.117150] [Medline: 19995754]

24. Institut für Arbeitsmarkt- und Berufsforschung. 2011. Daten zur kurzfristigen Entwicklung von Wirtschaft und Arbeitsmarkt URL: https://www.iab.de/de/publikationen/jahresbericht/jb2011.aspx [accessed 2020-02-28]

25. Bundeszentrale für politische Bildung. 2011. Geleistete Arbeitsstunden je Erwerbstätigem pro Jahr, Produktivität je Erwerbstätigenstunde, 1970-2012 URL: https://www.bpb.de/nachschlagen/zahlen-und-fakten/soziale-situation-in-deutschland/ 61711/arbeitszeit [accessed 2020-02-28]

26. Ziemssen T, Kern R, Cornelissen C. The PANGAEA study design - a prospective, multicenter, non-interventional, long-term study on fingolimod for the treatment of multiple sclerosis in daily practice. BMC Neurol 2015 Jun 18;15(1):93 [FREE Full text] [doi: 10.1186/s12883-015-0342-0] [Medline: 26084334]

27. Vormfelde SV, Ortler S, Ziemssen T. Multiple Sclerosis Therapy With Disease-Modifying Treatments in Germany: The PEARL (ProspEctive phArmacoeconomic cohoRt evaluation) Noninterventional Study Protocol. JMIR Res Protoc 2016 Feb 04;5(1):e23 [FREE Full text] [doi: 10.2196/resprot.4473] [Medline: 26846334]

28. Koo TK, Li MY. A Guideline of Selecting and Reporting Intraclass Correlation Coefficients for Reliability Research. Journal of Chiropractic Medicine 2016 Jun;15(2):155-163. [doi: 10.1016/j.jcm.2016.02.012]

29. Doward L, McKenna S, Meads D, Twiss J, Eckert B. The development of patient-reported outcome indices for multiple sclerosis (PRIMUS). Mult Scler 2009 Sep;15(9):1092-1102. [doi: 10.1177/1352458509106513] [Medline: 19556315]

30. Sharrack B, Hughes RA. The Guy's Neurological Disability Scale (GNDS): a new disability measure for multiple sclerosis. Mult Scler 1999 Aug;5(4):223-233. [doi: 10.1177/135245859900500406] [Medline: 10467380]

31. Graf J, Claes C, Greiner W, Uber A. Die deutsche Version des EuroQol-Fragebogens. J Public Health 1998 Mar;6(1):3-20. [doi: $10.1007 / \mathrm{bf02956350]}$

32. Greiner W, Claes C, Busschbach JJ, von der Schulenburg JM. Validating the EQ-5D with time trade off for the German population. Eur J Health Econ 2005 Jun;6(2):124-130. [doi: 10.1007/s10198-004-0264-z] [Medline: 19787848]

33. Atkinson MJ, Kumar R, Cappelleri JC, Hass SL. Hierarchical construct validity of the treatment satisfaction questionnaire for medication (TSQM version II) among outpatient pharmacy consumers. Value Health 2005;8 Suppl 1:S9-S24 [FREE Full text] [doi: $10.1111 /$ j.1524-4733.2005.00066.x] [Medline: $\underline{16336491]}$

34. Wundes A, Brown T, Bienen EJ, Coleman CI. Contribution of intangible costs to the economic burden of multiple sclerosis. J Med Econ 2010;13(4):626-632. [doi: 10.3111/13696998.2010.525989] [Medline: 20950249]

35. Kobelt G, Teich V, Cavalcanti M, Canzonieri AM. Burden and cost of multiple sclerosis in Brazil. PLoS One 2019;14(1):e0208837 [FREE Full text] [doi: 10.1371/journal.pone.0208837] [Medline: 30673707 ]

36. Ness NH, Schriefer D, Haase R, Ettle B, Cornelissen C, Ziemssen T. Differentiating societal costs of disability worsening in multiple sclerosis. J Neurol 2019 Dec 17. [doi: 10.1007/s00415-019-09676-4] [Medline: 31848738]

37. MS Zentrum Dresden. Zentrum für Klinische Neurowissenschaften. 2020. Multiple Sclerosis Health Resource Utilization Survey URL: http://msz.uniklinikum-dresden.de/ehealth/ms-hrs [accessed 2020-02-28]

\author{
Abbreviations \\ DMT: disease-modifying therapy \\ EDSS: Expanded Disability Status Score \\ EQ-5D: EuroQol-5 Dimensions \\ ICC: intraclass correlation coefficient \\ MS: multiple sclerosis \\ MS-HRS: Multiple Sclerosis Health Resource Utilization Survey \\ PRIMUS: Patient Reported Outcome Indices for Multiple Sclerosis \\ PRO: patient-reported outcome \\ RRMS: relapsing-remitting multiple sclerosis \\ TSQM: Treatment Satisfaction Questionnaire for Medication \\ UKNDS: UK Neurological Disability Scale
}


Edited by G Eysenbach; submitted 22.01.20; peer-reviewed by E d'Amico; comments to author 14.02.20; revised version received 18.02.20; accepted 19.02.20; published 17.03.20

Please cite as:

Ness NH, Haase R, Kern R, Schriefer D, Ettle B, Cornelissen C, Akguen K, Ziemssen T

The Multiple Sclerosis Health Resource Utilization Survey (MS-HRS): Development and Validation Study

$J$ Med Internet Res 2020;22(3):e17921

URL: http://www.jmir.org/2020/3/e17921/

doi: $10.2196 / 17921$

PMID: $\underline{32181745}$

CNils-Henning Ness, Rocco Haase, Raimar Kern, Dirk Schriefer, Benjamin Ettle, Christian Cornelissen, Katja Akguen, Tjalf Ziemssen. Originally published in the Journal of Medical Internet Research (http://www.jmir.org), 17.03.2020. This is an open-access article distributed under the terms of the Creative Commons Attribution License (https://creativecommons.org/licenses/by/4.0/), which permits unrestricted use, distribution, and reproduction in any medium, provided the original work, first published in the Journal of Medical Internet Research, is properly cited. The complete bibliographic information, a link to the original publication on http://www.jmir.org/, as well as this copyright and license information must be included. 